\title{
Evaluación de la capacidad antioxidante y el índice glicémico de los frutos promisorios amazónicos del Perú
}

Rosa Oriondo, Rubén Valdivieso, Raquel Oré, Inés Arnao, Miriam Palomino, Enriqueta Estrada

Objetivos: Determinar la capacidad antioxidante y el índice glicémico (IG) de frutos promisorios amazónicos del Perú. Diseño: Cuantitativo, descriptivo, transversal.

Institución: Centro de Investigación de Bioquímica y Nutrición, Facultad de Medicina, UNMSM.

Material biológico: Ratas albinas machos y frutos amazónicos.

Intervenciones: Se utilizó 12 ratas con peso aproximado de $250 \mathrm{~g}$, para determinar el IG de los frutos amazónicos. En los frutos se determinó la capacidad antioxidante mediante el método de DPPH, y contenido de fenoles totales mediante el reactivo de Folin-Ciocalteu.

Principales medidas de resultados: Se determinó IG, capacidad antioxidante y contenido de fenoles.

Resultados: Los IG: cajú 76; cajá 74; caimito 71,6 ; mango ciruela 59,7; pitujaya 51,8 y arazá 43,8. La capacidad antioxidante fue: arazá $268 \%$, caimito $302 \%$, pitujaya $524 \%$, cajú $107 \%$, cajá $201 \%$ y mango ciruela $353 \%$. Referente al contenido de fenoles: arazá 393,75 mg\%; caimito 562,50 mg\%; pitujaya 125 mg\%; cajú 875 mg\%; cajá 668,75 mg\% y mango ciruela $6818,75 \mathrm{mg} \%$.

Conclusiones: Los IG del cajú, cajá, caimito y mango ciruelas fueron altos, la pitujaya medio y el arazá bajo. Los frutos estudiados tuvieron alta capacidad antioxidante y contenido alto de fenoles.

Palabras clave: Frutos amazónicos, capacidad antioxidante, índice glicémico. 